\title{
Task-Technology Fit in Manufacturing: Examining Human-Machine Symbiosis through a Configurational Approach
}

\author{
Patrick Mikalef ${ }^{1,2}$ Hans Yngvar Torvatn ${ }^{1}$ and Emrah Arica ${ }^{1}$ \\ ${ }^{1}$ SINTEF Digital, S. P. Andersens veg 5 7031, Trondheim, Norway \\ ${ }^{2}$ Norwegian University of Science and Technology, Sem Saelands Vei 7-9 7491, Trondheim, \\ Norway \\ \{patrick.mikalef, hans.torvatn, emrah.arica\}@sintef.no
}

\begin{abstract}
With the last few years seeing an increased introduction of technological innovations in factories, one of the most pressing issues is how these technologies can be deployed to optimally support the activities of professionals that are actually utilizing them. Despite heavy investments in novel technologies, there are often negative consequences for the human factor, particularly when there is a lack of alignment between the task that it is used towards and the fit in terms of human training and the needs it is targeted to fulfil. In this research we build on the Task-technology Fit theory and a sample of 182 professionals working in Norway and explore the configurations of elements that drive positive impacts when introducing digital technologies to support factory work. We analyze data through a fuzzy set qualitative comparative analysis (fsQCA) method and demonstrate that there are several different combinations of conditions that can deliver positive impacts.
\end{abstract}

Keywords: Task-technology fit, human-machine symbiosis, fsQCA

\section{Introduction}

While there have been substantial investments in digital technologies for manufacturing purposes over the last few years [1], a critical issue is that in many cases the technologies used to support tasks of professionals are often not used as intended, or even not adopted at all [2]. Some studies have highlighted that the intended value from investments in novel technologies is not actually realized. A sizeable number of studies suggest that the underlying cause of this is due to a miss-match between what is needed from the human side in relation to work activities and what is provided by the technology [3]. In fact, some researchers have reported that professionals working in the manufacturing industry often have trouble adopting and routinizing newly introduced technologies [4]. This leads to negative impacts on their job performance when they have to utilize such systems [5]. Nevertheless, this problem is not strictly identified in the domain of manufacturing and factory work, and has been a core concern in several other domains including the education, banking and financial sector, and even 
high-tech companies [6, 7]. It is surprising to see that the human factor has received only limited attention to date when taking into account the huge costs invested by companies to develop and adopt such technologies [8].

A growing body of research underscores on the importance of looking into the symbiosis between humans and machine $[9,10]$. The main idea is that human cyberphysical systems should serve to improve human abilities to dynamically interact with machines, and improve human physical-, sensing- and cognitive capabilities [2]. The underlying logic of this perspective is that by optimizing human-machine cooperation organizations can realize improvements in performance and efficiency [11]. In doing so there have been a number of different approaches into examining how humans and machines can complement each other capabilities and create value, and what factors influence human intention to adopt and use technologies such as the Technology Adoption Model (TAM) and the Unified Theory of Acceptance and Use of Technology (UTAUT) [12]. Nevertheless, these models don't account for which technologies best fit which task. The theory of task-technology fit (TTF) has been a particularly prominent perspective and well-suited in explaining how specific job-related tasks, aspects of the technology, as well as use practices coalesce to create fit, and subsequently positive impacts [13]. The TTF theory has received substantial attention within other fields such as the Information Systems domain, yet when examining the adoption of technologies to support manufacturing and factory work studies are still scarce [14]. There is a growing perspective within the broader field of technology adoption that there may be several different ways by which technological solutions can be used to support professionals work activities [15]. The underlying premise is that individuals in their work are faced with different tasks that they must complete.

The objective of this study is to adopt a TTF theoretical perspective, and examine which are those combinations of tasks, technology, and individual use practices that fit together and lead to positive impacts in the context of manufacturing and factory professionals work. We build on a recent large-scale empirical survey conducted with 182 professionals, and by applying the novel methodological approach fuzzy set qualitative comparative analysis (fsQCA) we reveal several configurations that lead to positive outcomes for job-related activities. In this way we can identify a number of different tasks, the aspects pertinent to technology that best fit task requirements, as well as individual use and adoption practices that facilitate optimal fit.

\section{Background}

To explore how technologies deployed within the manufacturing domain can contribute to positive outcomes of work performance, we develop this research on the tasktechnology fit theory [13]. Based on TTF theory, digital technologies will be more likely to yield a positive impact when the functionalities they deliver can fit the tasks individuals must undertake. Since its inception, the theory has been extended in several ways, with the latest studies recognizing how individuals use these technologies as well as the design and training practices surrounding adoption and diffusion, have an important role on performance of technology use [16]. Hence, the task-technology 
fit theory has been applied at various levels of analysis, examining effects on individuals and groups [17], as well as in many different contexts, from specific technologies [18] to effects on industries or particular professions [19]. When looking into the area of manufacturing and factory work, there has been very limited work following this approach. Despite this, recent work has recognized the importance of the human factor highlighting that there needs to be alignment between the jobs humans must perform, the digital technologies introduced to support them, and the training they receive to adopt such systems into their work [20]. To determine how these aspects jointly contribute to drive positive impacts in job performance, we follow a configurational approach in data analysis [21].

Configurational approaches have been growing in interest in the IS and technology management community over the past few years [22, 23]. Such approaches have the advantage that they enable the identification of multiple different paths, or solutions, that lead to an outcome of interest [24]. In practical terms, this means that in the case of positive impacts of digital technology use in the manufacturing and factory work context, it would be possible to detect several successful cases of using technologies to perform specific tasks, along with the individual use characteristics that describe them. Nevertheless, in spite of the promise of such approaches, there is still very limited research in exploring how the different aspects pertinent to task, technology, and individual use coalesce to drive fit, and as a result positive impacts in the factory and manufacturing workplace [25]. The bulk of research building on the task-technology fit theory has emphasized on the two main concepts (i.e. task and technology) [26], while a growing stream of research incorporates in the investigation the role of individuals and how technologies are deployed and routinized in work activities [27]. An increasing number of research is looking into the formal and informal mechanisms of adopting the use of technologies in the workplace, acknowledging the fact that just as important as the technology itself to support a task are the practices through which they are embedded in work [28].

\section{$3 \quad$ Method}

\subsection{Data Collection}

To examine the configurations of elements regarding tasks, technology, and individual use context that lead to positive impacts in the work environment, a survey instrument was developed. A professional data collection company was commissioned with conducting phone polls to individuals throughout Norway using a database of approximately 10.000 individuals in a variety of different industries, including those of factory and manufacturing workers amongst others. No specific areas of manufacturing were selected, and respondents covered tasks of several different functions. The scales of the questionnaire are described in section 3.2. The callers informed participants about the purpose of the study and asked respondents to answer a number of questions. The data gathering process lasts roughly four months (May 2017-August 2017), and the average time for answering the questions of the survey was 23 minutes. A total of 182 complete responses were received from the manufacturing industry. From 
this sample, most responses came from the age-groups 45-59 years (38\%) and 30-44 years $(37 \%)$. In terms of gender distribution, the largest proportion of the sample consisted of male employees (72\%) while females accounted for $28 \%$ of the sample. When looking at the educational background of respondents, most of them had as a highest academic qualification a degree from high school (42.9\%), while $35.67 \%$ had until 4 years in higher education (equivalent to bachelor's degree).

Table 1. Descriptive statistics of sample respondents' profile

\begin{tabular}{lll}
\hline & Sample $(\mathrm{N}=182)$ & Percentage $(\%)$ \\
\hline Age & & \\
Under 30 & 33 & $18 \%$ \\
30-44 years old & 67 & $37 \%$ \\
45-59 years old & 69 & $38 \%$ \\
More than 60 years old & 13 & $7 \%$ \\
Highest Educational Level & & \\
Primary school & 6 & $3.3 \%$ \\
High school & 78 & $42.9 \%$ \\
Higher education (less than 4 years) & 65 & $35.7 \%$ \\
Higher education (more than 4 years) & 33 & $18.1 \%$ \\
\hline
\end{tabular}

\subsection{Measurements}

Regarding attributes relevant to the task itself, we utilized measures that included questions on the types of tasks in which digital technologies were used, the difficulty ad time-criticality of the task, if the level of non-routineness. Specifically, we measured on a 5-point likert scale the frequency in which respondents used digital technology for core tasks, reporting and documentation tasks, and information/coordination [29]. To determine if they held positions that required leadership skills, we asked respondents to indicate if they had no leadership responsibilities, personnel, managerial, or both. Finally, we asked respondents to indicate how often they were expected to work outside of paid work hours [30].

Concerning technology-related characteristics we followed a similar approach, looking at different aspects related to functionality and user-friendliness, while also incorporating specific types of devices in the questions that are commonly used by manufacturing professionals. We captured the extent to which respondents believed that digital technologies they used in the jobs were functional and reliable, userfriendly, and adaptable [31]. Furthermore, we assessed the extent to which respondents need to use different types of devices to perform their work such as personal computers, mobile devices (e.g. smart phones, tablets and portable equipment), and wearables (smart glasses, smartwatch), or augmented reality technologies [32].

In terms of individual use context, we tried to capture elements that were relevant to how individuals adopt and utilize novel digital technologies, as well as what types of support mechanisms are set up to facilitate such usage. In congruence with past empirical studies we include aspects that can affect how easily and well individuals utilize digital technology [13]. We examine the degree to which individuals have a 
support network from colleagues when using digital technologies, the extent to which they have been trained to use the latest digital technologies in their organizations (e.g. courses, e-learning, self-education through reading), as well as the level to which they have been involved in the joined planning of introducing new digital technologies [33]. Finally, when it comes to examining the impacts of digital technology use in the manufacturing sector, we operationalize this variable as the level to which the quality of work gets better, work is done fast, and the level to which the work performed relies on the use of digital technologies [34].

\section{$4 \quad$ Analysis}

To identify the configurations of task, technology, and use practice lead to lead to positive or negative work impact we employ a fuzzy-set Qualitative Comparative Analysis (fsQCA) approach. Applying such an approach is particularly relevant to the case of digital technology usage within the manufacturing context, since depending on the type of task, and characteristics of the individual, different digital technologies and use support mechanisms may be more or less relevant in producing positive impacts [35]. A first step of performing a fsQCA analysis requires that we calibrate dependent and independent variables into fuzzy or crisp sets. To calibrate continuous variables such as the ones we have utilized in the survey into fuzzy sets we followed the method proposed by Ragin [36]. Following this procedure, the degree of set membership is based on three anchor values. These include a full set membership threshold value (fuzzy score $=0.95$ ), a full non-membership value (fuzzy score $=0.05$ ), and the crossover point (fuzzy score $=0.50$ ) [37]. Based on prior empirical research we computed percentiles for each construct so that the upper 25 percentiles serve as the threshold for full membership; the lower 25 percentiles for full non-membership; and the 50 percentiles represent the cross-over point. The results of the analysis are depicted in the table below and discussed in the final section.

Table 2. Configurations leading to high work performance

\begin{tabular}{|l|}
\hline Configuration \\
\hline Task \\
\hline Core task \\
\hline Reporting and documentation task \\
\hline Information/Coordination task \\
\hline Leadership \\
\hline Non-Routineness \\
\hline Technology \\
\hline Reliability \\
\hline User-friendliness \\
\hline Adaptability/Flexibility \\
\hline Personal computer \\
\hline Mobile devices \\
\hline
\end{tabular}

\begin{tabular}{|c|c|c|c|c|}
\hline \multicolumn{5}{|c|}{ Positive Impacts } \\
\hline 1 & 2 & 3 & 4 & 5 \\
\hline & & & & \\
\hline$\bullet$ & & $\bullet$ & $\bullet$ & \\
\hline & $\bullet$ & & $\otimes$ & \\
\hline & $\bullet$ & $\bullet$ & & $\bullet$ \\
\hline & & & & $\bullet$ \\
\hline & $\otimes$ & & $\otimes$ & \\
\hline & & & & \\
\hline & $\bullet$ & $\bullet$ & $\bullet$ & $\bullet$ \\
\hline$\bullet$ & & $\bullet$ & $\bullet$ & $\bullet$ \\
\hline$\bullet$ & & & $\bullet$ & \\
\hline & $\bullet$ & & $\otimes$ & \\
\hline & & $\bullet$ & & $\bullet$ \\
\hline
\end{tabular}




\begin{tabular}{|c|}
\hline Wearables \\
\hline Augmented Reality \\
\hline Individual Use Context \\
\hline Colleague support \\
\hline Training \\
\hline Planning participation \\
\hline
\end{tabular}

\begin{tabular}{|l|}
\hline Consistency \\
\hline Raw Coverage \\
\hline Unique Coverage \\
\hline Overall Solution Consistency \\
\hline Overall Solution Coverage \\
\hline
\end{tabular}

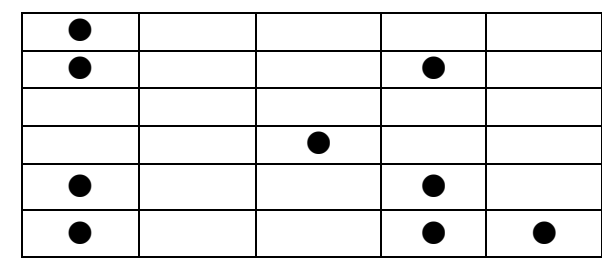

\begin{tabular}{|c|c|c|c|c|}
\hline 0.86 & 0.91 & 0.93 & 0.83 & 0.88 \\
\hline 0.27 & 0.18 & 0.13 & 0.18 & 0.21 \\
\hline 0.11 & 0.08 & 0.09 & 0.10 & 0.04 \\
\hline \multicolumn{5}{|c|}{0.86} \\
\hline \multicolumn{5}{|c|}{0.42} \\
\hline
\end{tabular}

\section{Discussion}

This study finds that there are different combinations of technologies, features, and mechanisms to routinize depending on the task at hand. Furthermore, the results indicate that tasks that revolve around core tasks, such as those in the workstation can be improved the right combination of technologies and attributes in their design, coupled with the necessary training practices. The black circles denote a presence of a condition while the crossed-out ones an absence of it. For instance, in column 2, the solution reads as follows. When the task of the worker includes activities of reporting and documentation and information coordination and is a routine activity, then high reliability coupled with the use of a personal computer and a collegial support regime are sufficient to drive positive work performance. Likewise, other solutions show different tasks and combinations of them, pinpointing to certain activities within the work environment and how they can optimally be enhanced by means of digital technologies. What is interesting to observe also is that apart from the physical technologies themselves, there are also functional characteristics and design principles that need to be considered. In addition, the strategies applied to deploy and routinize such technologies are identified in solutions. These solutions are by no means exhaustive and can be examined on an even more granular level, nevertheless, they do illustrate a novel approach for uncovering combinations of elements around the use of technology that lead to positive outcomes. Future research can extend on this method and identify how human-machine symbiosis can be optimized.

\section{References}

1. Bartodziej, C.J.: The concept industry 4.0: an empirical analysis of technologies and applications in production logistics. Springer (2016)

2. Romero, D., Bernus, P., Noran, O., Stahre, J., Fast-Berglund, Å.: The operator 4.0: human cyber-physical systems \& adaptive automation towards human-automation symbiosis work systems. In: IFIP International Conference on Advances in Production Management Systems, pp. 677-686. Springer, (Year) 
3. Shu, Q., Tu, Q., Wang, K.: The impact of computer self-efficacy and technology dependence on computer-related technostress: A social cognitive theory perspective. International Journal of Human-Computer Interaction 27, 923-939 (2011)

4. Kaufman, B.E.: Strategic human resource management research in the United States: A failing grade after 30 years? Academy of Management Perspectives 26, 12-36 (2012)

5. Golightly, D., Sharples, S., Patel, H., Ratchev, S.: Manufacturing in the cloud: A human factors perspective. International Journal of Industrial Ergonomics 55, 12-21 (2016)

6. Pai, F.-Y., Huang, K.-I.J.T.F., Change, S.: Applying the technology acceptance model to the introduction of healthcare information systems. 78, 650-660 (2011)

7. Dahnil, M.I., Marzuki, K.M., Langgat, J., Fabeil, N.F.: Factors influencing SMEs adoption of social media marketing. Procedia-social and behavioral sciences 148, 119-126 (2014)

8. Romero, D., Noran, O., Stahre, J., Bernus, P., Fast-Berglund, Å.: Towards a human-centred reference architecture for next generation balanced automation systems: human-automation symbiosis. In: IFIP International Conference on Advances in Production Management Systems, pp. 556-566. Springer, (Year)

9. Romero, D., Stahre, J., Wuest, T., Noran, O., Bernus, P., Fast-Berglund, Å., Gorecky, D.: Towards an operator 4.0 typology: a human-centric perspective on the fourth industrial revolution technologies. In: Proceedings of the International Conference on Computers and Industrial Engineering (CIE46), Tianjin, China, pp. 29-31. (Year)

10.Jarrahi, M.H.J.B.H.: Artificial intelligence and the future of work: human-AI symbiosis in organizational decision making. 61, 577-586 (2018)

11.Jones, A.T., Romero, D., Wuest, T.: Modeling agents as joint cognitive systems in smart manufacturing systems. Manufacturing Letters 17, 6-8 (2018)

12.Venkatesh, V., Davis, F.D.: A theoretical extension of the technology acceptance model: Four longitudinal field studies. Management science 46, 186-204 (2000)

13.Goodhue, D.L., Thompson, R.L.J.M.q.: Task-technology fit and individual performance. 213-236 (1995)

14.Tjahjono, B., Fakun, D., Greenough, R.M., Kay, J.M.: Evaluation of a manufacturing task support system using the task technology fit model. (2001)

15.Kim, M.J., Chung, N., Lee, C.K., Preis, M.W.J.I.J.o.T.R.: Motivations and use context in mobile tourism shopping: Applying contingency and task-technology fit theories. 17, 13-24 (2015)

16.Aljukhadar, M., Senecal, S., Nantel, J.J.I., Management: Is more always better? Investigating the task-technology fit theory in an online user context. 51, 391-397 (2014)

17.Strong, D.M., Volkoff, O.J.M.q.: Understanding Organization-Enterprise system fit: A path to theorizing the information technology artifact. 731-756 (2010)

18.Furneaux, B.: Task-technology fit theory: A survey and synopsis of the literature. Information systems theory, pp. 87-106. Springer (2012)

19.Cady, R.G., Finkelstein, S.M.J.T., e-Health: Task-technology fit of video telehealth for nurses in an outpatient clinic setting. 20, 633-639 (2014)

20.Gill, K.S.: Human machine symbiosis: The foundations of human-centred systems design. Springer Science \& Business Media (2012)

21.Mikalef, P., Pateli, A., Batenburg, R.S., Wetering, R.v.d.: Purchasing alignment under multiple contingencies: a configuration theory approach. Industrial Management \& Data Systems 115, 625-645 (2015) 
22.Mikalef, P., Pateli, A.: Information technology-enabled dynamic capabilities and their indirect effect on competitive performance: Findings from PLS-SEM and fsQCA. Journal of Business Research 70, 1-16 (2017)

23.van de Wetering, R., Mikalef, P., Helms, R.: Driving organizational sustainability-oriented innovation capabilities: a complex adaptive systems perspective. Current Opinion in Environmental Sustainability 28, 71-79 (2017)

24.Fiss, P.C.: Building better causal theories: A fuzzy set approach to typologies in organization research. Academy of Management Journal 54, 393-420 (2011)

25.Schneider, M.R., Schulze-Bentrop, C., Paunescu, M.: Mapping the institutional capital of high-tech firms: A fuzzy-set analysis of capitalist variety and export performance. Journal of International Business Studies 41, 246-266 (2010)

26.Or, C.K., Karsh, B.-T.J.J.o.t.A.M.I.A.: A systematic review of patient acceptance of consumer health information technology. 16, 550-560 (2009)

27.Kim, D.: Adoption of personal information system: Innovation diffusion theory and tasktechnology fit. In: Allied Academies International Conference. Academy of Management Information and Decision Sciences. Proceedings, pp. 50. Jordan Whitney Enterprises, Inc, (Year)

28.Mikalef, P., Boura, M., Lekakos, G., Krogstie, J.: Big data analytics capabilities and innovation: the mediating role of dynamic capabilities and moderating effect of the environment. British Journal of Management 30, 272-298 (2019)

29.Weiseth, P.E., Munkvold, B.E., Tvedte, B., Larsen, S.: The wheel of collaboration tools: a typology for analysis within a holistic framework. In: Proceedings of the 2006 20th anniversary conference on Computer supported cooperative work, pp. 239-248. ACM, (Year)

30.Cane, S., McCarthy, R.J.J.o.C.I.S.: Analyzing the factors that affect information systems use: a task-technology fit meta-analysis. 50, 108-123 (2009)

31.Lin, T.-C.J.C.C., Informatics, Nursing: Mobile nursing information system utilization: the task-technology fit perspective. 32, 129-137 (2014)

32.Metcalf, D., Milliard, S.T., Gomez, M., Schwartz, M.J.I.p.: Wearables and the internet of things for health: Wearable, interconnected devices promise more efficient and comprehensive health care. 7, 35-39 (2016)

33.Mikalef, P.: Developing IT-enabled dynamic capabilities: a service science approach. In: International Conference on Business Informatics Research, pp. 87-100. Springer, (Year)

34.Chung, S., Lee, K.Y., Kim, K.J.I., Management: Job performance through mobile enterprise systems: The role of organizational agility, location independence, and task characteristics. 51, 605-617 (2014)

35.Mikalef, P., Boura, M., Lekakos, G., Krogstie, J.: Big data analytics and firm performance: Findings from a mixed-method approach. Journal of Business Research 98, 261-276 (2019)

36.Ragin, C.C.: Qualitative comparative analysis using fuzzy sets (fsQCA). Configurational comparative methods 51, (2009)

37.Woodside, A.G.: Moving beyond multiple regression analysis to algorithms: Calling for adoption of a paradigm shift from symmetric to asymmetric thinking in data analysis and crafting theory. Elsevier (2013) 